\title{
Modelling recent and future climatic suitability for fasciolosis in Europe
}

\author{
Cyril Caminade ${ }^{1,2}$, Jan van Dijk², Matthew Baylis ${ }^{2,3}$, Diana Williams ${ }^{4}$ \\ ${ }^{1}$ School of Environmental Sciences, University of Liverpool, Liverpool, UK; ${ }^{2}$ Department of Epidemiology and \\ Population Health, Institute of Infection and Global Health, University of Liverpool, Liverpool, UK; ${ }^{3}$ NIHR \\ Health Protection Research Unit in Emerging and Zoonotic Infections, Liverpool, UK; ${ }^{4}$ Department of \\ Infection Biology/School of Veterinary Science, Institute of Infection and Global Health, University of \\ Liverpool, Liverpool, UK
}

\begin{abstract}
Fasciola hepatica is a parasitic worm responsible for fasciolosis in grazed ruminants in Europe. The free-living stages of this parasite are sensitive to temperature and soil moisture, as are the intermediate snail hosts the parasite depends on for its life-cycle. We used a climate-driven disease model in order to assess the impact of recent and potential future climate changes on the incidence of fasciolosis and to estimate the related uncertainties at the scale of the European landmass. The current climate appears to be highly suitable for fasciolosis throughout the European Union with the exception of some parts of the Mediterranean region. Simulated climatic suitability for fasciolosis significantly increased during the 2000s in central and northwestern Europe, which is consistent with an observed increased in ruminant infections. The simulation showed that recent trends are likely to continue in the future with the estimated pattern of climate change for northern Europe, possibly extending the season suitable for development of the parasite in the environment by up to four months. For southern Europe, the simulated burden of disease may be lower, but the projected climate change will increase the risk during the winter months, since the simulated changes in temperature and moisture support the development of the free-living and intra-molluscan stages between November and March. In the event of predicted climate change, F. hepatica will present a serious risk to the health, welfare and productivity of all ruminant livestock. Improved, bespoke control programmes, both at farm and region levels, will then become imperative if problems, such as resistance of the parasite associated with increased drug use, are to be mitigated.
\end{abstract}

Keywords: Fasciola hepatica, fasciolosis, climate change, Europe.

\section{Introduction}

Fasciola hepatica, the common liver fluke, is a parasitic flatworm of the class Trematoda. It infects the liver of various mammals, including humans, causing fasciolosis. For the asexual reproduction part of its life cycle the parasite requires an intermediate host, such as amphibious mud snails, e.g. Galba truncatula. F. hepatica has a worldwide distribution and causes great economic losses, mainly in sheep and to a lesser extent in cattle (Behm and Sangster, 1999). The most frequent, and major economic impact of $F$. hepatica, is sub-clinical infection leading to reduced meat/milk production as well as reduction in the value of fibre, fleece/hide and skin products (Kaplan, 2001). However, during severe, acute infections, mortality

\footnotetext{
Corresponding author:

Cyril Caminade

Institute of Infection and Global Health

The Farr Institute@HeRC

University of Liverpool, Liverpool L69 3GL, United Kingdom

Tel. +44 151 795-8322

E-mail: Cyril.Caminade@liverpool.ac.uk
}

rates as high as $50 \%$ have been reported in sheep (Fiss et al., 2013). The economic costs of fasciolosis have become increasingly important in the current economic climate with low profit margins in the livestock sector. In addition, $F$. hepatica is increasingly resistant to triclabendazole, one of the principal anthelmintic drugs used for its control (Sargison et al., 2007; Daniel et al., 2012). Recent climate change might also have favoured the spread and the observed increased in prevalence of fasciolosis in animals in the United Kingdom (UK) (Fox et al., 2011).

F. hepatica is favoured by wet and mild/warm climatic conditions, which are required to complete its life-cycle (Ollerenshaw and Rowlands, 1959; McCann et al., 2010). Water is generally assumed to be crucial for the survival and development of the parasite's free living stages as well as the snail intermediate hosts (Ollerenshaw and Rowlands, 1959). Temperature and soil evapotranspiration co-determine development of the parasite and snail hosts, and this is the key determinant to the seasonality of this infection (van Dijk et al., 2010). Given the parasite's climate sensitivity, fasciolosis is expected to respond to climate change; however, its dependence on both temperature and 
moisture means that projected outcomes are not straightforward. For example, a recent study of the impact of future climate change on fasciolosis risk in the UK shows that, despite a simulated long-term risk increase in most regions, some regions might experience a decrease in summer infections due to the expected restriction of water availability in the 2040s (Fox et al., 2011).

How climate change may affect incidence and distribution of fasciolosis has not yet been addressed at the European scale. We used here a climate-driven model for fasciolosis based on the forecasting system originally formulated by Ollerenshaw and Rowlands (1959) for Wales. We extrapolated this model to the European level in order to highlight how recent climate change might already have affected the risk of fasciolosis for the countries there, and we further wished to estimate how the disease burden might be affected in the future. To that end, we utilized an ensemble of climate models and emission scenarios to estimate the uncertainties in future projections. We also aimed to assess the relationship between simulated changes in climatic variables and outcome with respect to simulated disease risk for different future time periods. Finally, we provide recommendations and discuss caveats and future perspectives of this framework.

\section{Materials and methods}

\section{Model description}

The original Ollerenshaw $M t$ index (Ollerenshaw and Rowlands, 1959) quantifies and categorises the risk of acute fasciolosis in autumn/early winter based on rainfall and evapotranspiration during late spring to early autumn for the UK. It represents the monthly fasciolosis risk value as the outcome of a model dependent on the interactions between rainfall, temperature and the frequency of rainy days, and this was calculated as follows:

$$
M t=n \times\left(\frac{R}{25.4}-\frac{P}{25.4}+5\right)
$$

where $M t$ is the fasciolosis risk value $(0-100$ for a given month), $n$ the number of rainy days per month (defined as days with above $1 \mathrm{~mm}$ rainfall), $R$ the rainfall $(\mathrm{mm} / \mathrm{month})$ and $P$ the potential evapotranspiration $(\mathrm{mm} / \mathrm{month})$. For the calculation of $P$ we used Hargreaves' equation (Hargreaves and Samani, 1985), where $R a$ is the extra-terrestrial radiation in $\mathrm{MJm}^{-2}$ per day with $T_{\max }$ and $T_{\min }$ the maximum and minimum temperatures in ${ }^{\circ} \mathrm{C}$, respectively:

$$
P=0.0023 \times 0.408 \times R a \times\left(\frac{T_{\max }+T_{\min }}{2}+17.8\right) \sqrt{T_{\max }-T_{\min }}
$$

(Eq. 2)

$R a$, depending on the latitude and the day of year, was assumed to be constant from year to year and it was calculated based on a daily time step (WATFLOOD, 2002). Mt was set to zero if the mean monthly temperature was below $10^{\circ} \mathrm{C}$ to reflect the low development thresholds for both the free-living stages of F. hepatica and its main snail intermediate host in Europe, G. truncatula (Mas-Coma et al., 2005). When the model was originally formulated for Anglesey in the UK, mean temperatures were only above $+10^{\circ} \mathrm{C}$ between the months of May and October; hence only these months were included in the original model. Given that temperatures have increased over the past five decades and are predicted to increase in the future, plus the fact that other European regions might be climatically suitable for a longer transmission season, we included all months in the $M t$ calculation. The monthly $M t$ values were added together to provide projected seasonal, annual and long-term estimates of the risk. When the monthly $M t$ value reaches 100, it can be assumed that the moisture level is sufficiently high to permit parasite development. Consequently, the monthly $M t$ values were capped at 100 . In drier, southern European regions, $M t$ can become negative when the amount of evapotranspiration surpasses precipitation. Therefore, we capped the $M t$ values at 0 when they were negative. Ollerenshaw and Rowlands (1959) compared winter and summer $M t$ values (aggregated over a 6-month period) with four critical thresholds: $M t<300=$ little or no disease; $M t$ between 300 and $400=$ occasional losses; $M t$ between 400 and $474=$ disease prevalent; $M t$ above $474=$ serious epidemic. As we aggregated the $M t$ values on an annual basis for the risk mapping, these thresholds might not be relevant for Europe. However, they were deemed useful as an indication of the level of the number of infections originally calculated for the UK.

\section{Datasets}

\section{Observed European climate data}

We employed a gridded climate dataset $\left(0.25^{\circ} \mathrm{x}\right.$ $0.25^{\circ}$ ) based on weather station measurements for Europe. Daily data for rainfall, mean, minimum and 
maximum temperature fields for the period 19502013 are available from the original dataset by Haylock et al. (2008) and recent updates can be accessed at http://eca.knmi.nl/download/ensembles/ download.php. The most up-to-date version (v.10) of this observed climate dataset (EOBS) was employed to estimate the impact of recent changing climatic conditions on the European F. hepatica burden.

\section{Climate model experiments}

We used a subset of five global climate models (HadGem2-ES; IPSL-CM5A-LR; MIROC-ESMCHEM; GFDL-ESM2M; and NorESM1-M) produced within the coupled Model Inter-comparison project 5 (Taylor et al., 2012). This subset was selected to give a wide range of possible/expected temperature and rainfall changes for the future (Warszawski et al., 2014). The simulated climatic variables were further calibrated by the Potsdam Institute for Climate Impact Research within the Inter-Sectoral Impact Model Intercomparison Project (ISI-MIP) framework (Warszawski et al., 2014). This was carried out to ensure statistical agreement between the climate model outputs and the observed Watch Forcing Dataset for the recent context, e.g. 1960-1999 (Hempel et al., 2013). The Representative Concentration Pathways (RCP) scenarios (RCP-2.6, RCP-4.5, RCP-6 and RCP-8.5) represent a range of "radiative forcings", i.e. changes in the balance between incoming and outgoing radiation with respect to the atmosphere (Moss et al., 2010), varying from the mildest (RCP-2.6) to the most extreme (RCP-8.5) emission scenario. All four different RCPs were available for five bias-corrected climate models. Future model integrations were undertaken for three time windows (20-year averages): 2020s (2011 to 2030); 2050s (2041-2060) and 2080s (2071-
2090). All climate model experiments were re-gridded to a uniform half-degree square grid at the global scale, and we extracted the European domain $\left[35.5^{\circ} \mathrm{N}-71^{\circ} \mathrm{N}, 12^{\circ} \mathrm{W}-30^{\circ} \mathrm{E}\right]$.

\section{Host density layers}

Animal densities (sheep, goat and cattle) were derived from the Livestock Geo-Wiki database (Robinson et al., 2014). This dataset is global and we interpolated the data to a regular $0.25^{\circ} \times 0.25^{\circ}$ grid covering Europe. We used 2006 data from the Gridded Livestock of the World v2.0 as an extra layer to identify regions with both high animal densities and large climatic suitability. This dataset can be accessed at http://www.livestock.geo-wiki.org/home-2/.

\section{Model integration}

We employed the EOBS climate data to calculate $M t$ outputs for Europe with respect to the recent period. We then used the ISI-MIP bias-corrected climate model ensemble to drive the $M t$ model in order to estimate future changes in climatic suitability for $F$. hepatica in Europe.

\section{Results}

Cattle densities were found to be high in most of the UK, Ireland, Benelux, northern and central France, north-western and southern Germany, northern Italy, Denmark, northern Switzerland and to a lesser extent over southern Sweden, Austria, Poland, Belarus, northern Romania, Ukraine, Slovenia, north-western Spain and Albania (Fig. 1a). Small ruminants such as goat and sheep generally have less resilience to $F$. hepatica infections. There were high densities in sheep and (a) Cattle

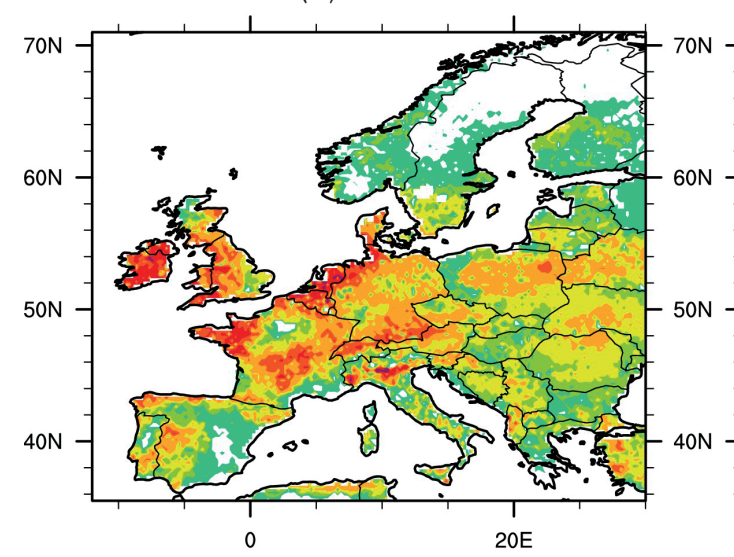

(b) Goat and sheep

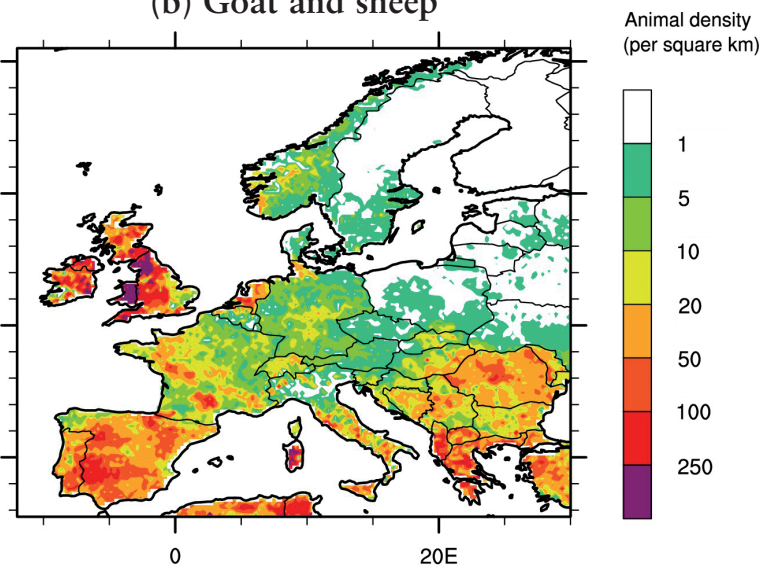

Fig. 1. The distribution of cattle (a), goat and sheep (b) in Europe. 
goats in most of the UK, Spain, Portugal, southern and north-western France, the Netherlands, the coastal areas of Norway, mainland Italy, the islands Corsica, Sardina and Sicily, Serbia, Bosnia and Herzegovina, Romania, Bulgaria, Greece, Albania, Macedonia and Turkey (Fig. 1b).

The climate-driven risk of fasciolosis across Europe over the past four decades is shown in Fig. 2. Regardless of the time period considered, the climate appears to be suitable for fasciolosis over the western side of the UK, Ireland, western France, northern Spain, western Portugal, northern Switzerland, southern Germany, western Austria, Slovenia and to a lesser extent along Italy's west-coast, Sicily, northwestern Germany, northern and southern Poland and western Ukraine. These areas also show large animal densities (Fig. 1). The risk due to climate significantly increased during the 2000s, especially in the UK, Ireland, Sicily, northern Switzerland, western Austria and southern Germany and to lesser extent in Benelux, Denmark and the southern coasts of Sweden and Norway (Fig. 2d). The months when climatic conditions were projected to be optimal for development of the parasite are May to October in most of western Europa, whilst suitable conditions occurred in all months except the warmest and driest summer months in Portugal (Fig. 3).

The impact of future climate change on $F$. hepatica risk in Europe is given in Fig. 4. Most climate modelbased simulations tend to overestimate $M t$ values due to an overestimation of simulated rainy days, even after bias correction (not shown). Focusing on relative changes (with respect to the 2020s), simulations for the late $21^{\text {st }}$ century driven by the extreme RCP-8.5 emission scenario, indicate that $M t$ annual values will significantly increase in north-western central Europe, e.g. France, Benelux, Germany, the UK and Ireland, while simulations driven by the lowest RCP-2.6 emission scenario a) $1970 \mathrm{~s}$

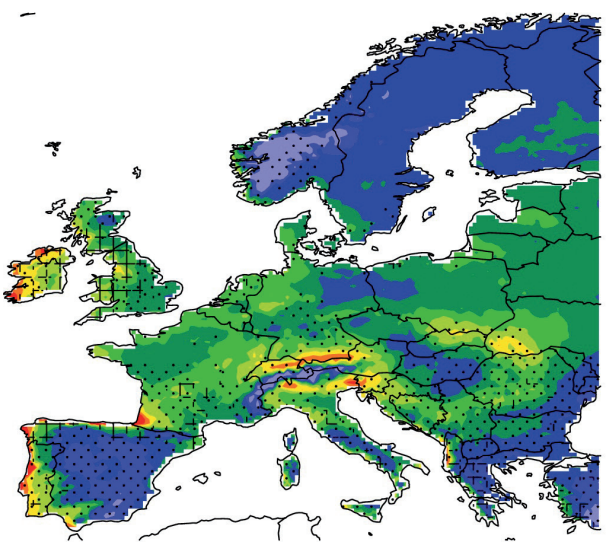

c) $1990 \mathrm{~s}$

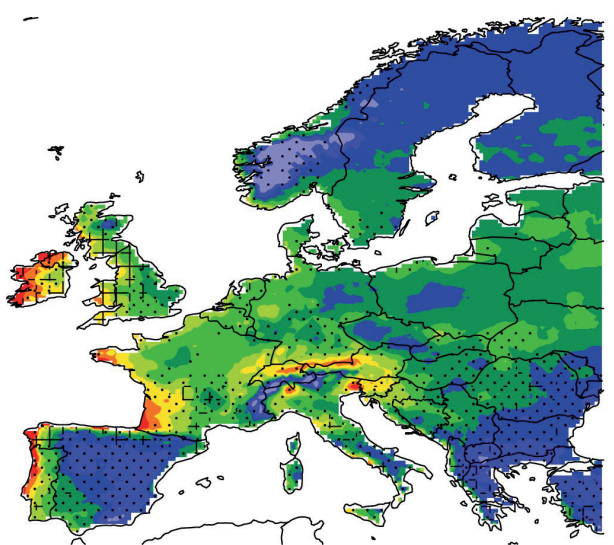

b) $1980 \mathrm{~s}$

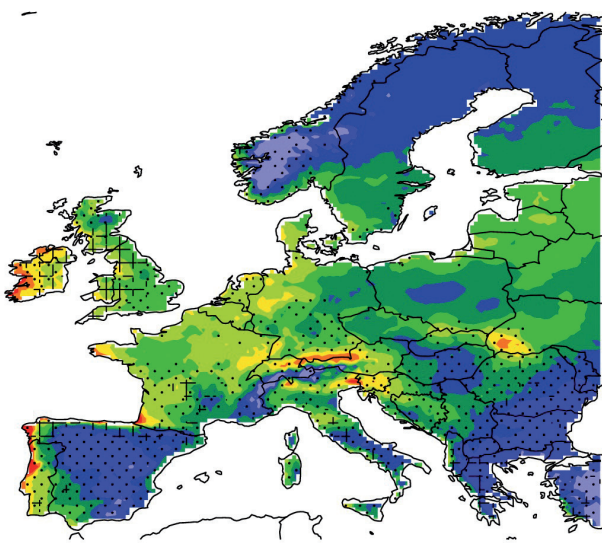

d) $2000 \mathrm{~s}$

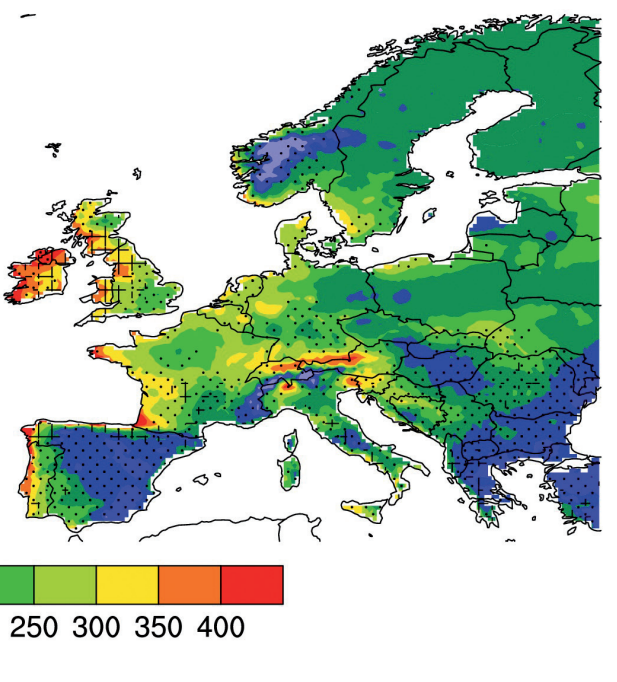

Fig. 2. Simulated annual $M t$ indices driven by the EOBS climate dataset. Animal densities (sheep and goat) above 5 and 100 animal per $\mathrm{km}^{2}$ are shown with dotted and gridded patterns, respectively. The $M t$ values should be compared to the four critical thresholds given in the model description. 

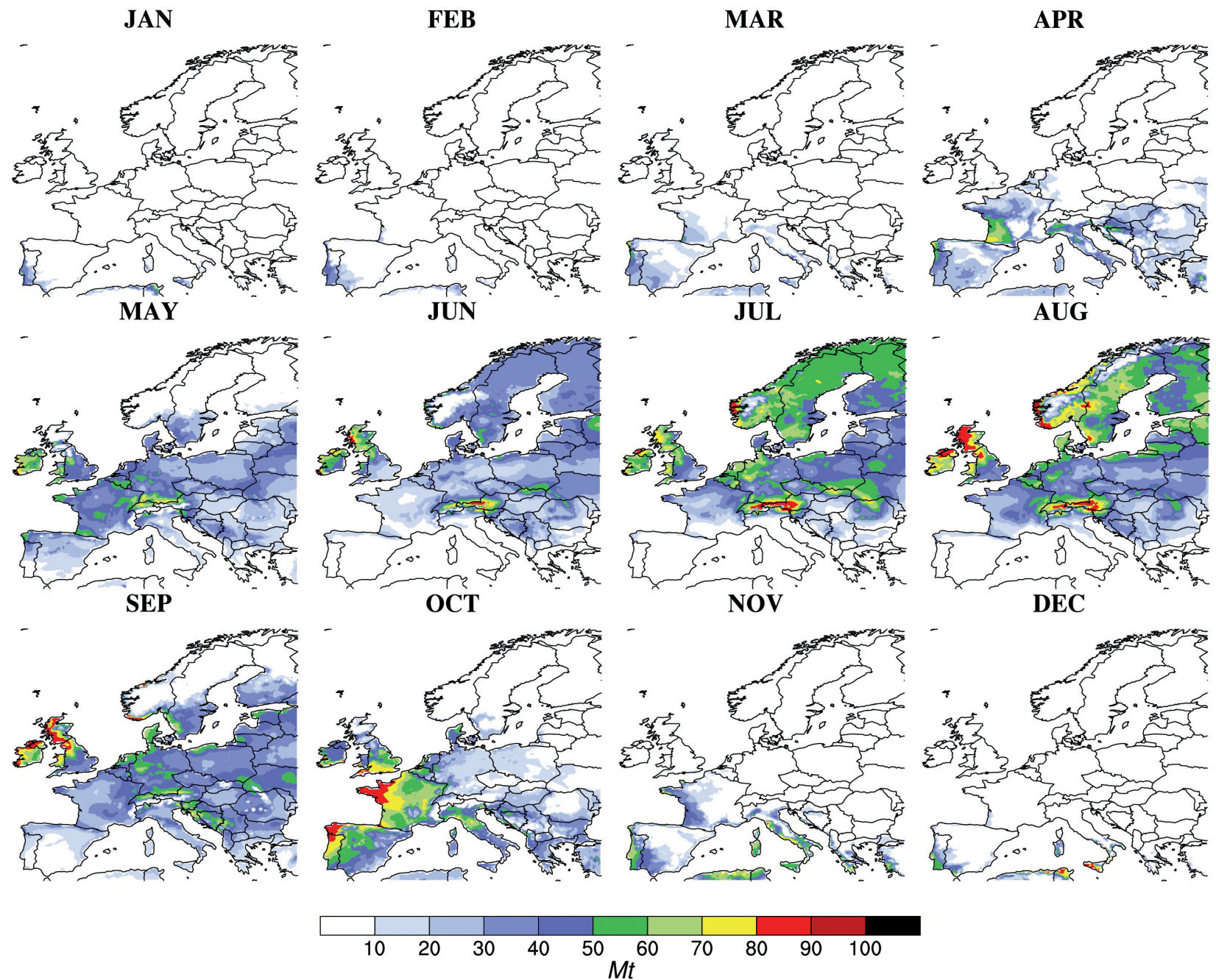

Fig. 3. F. hepatica mean seasonal cycle risk according to the $M t$ model based on the EOBS climate data at the $0.25^{\circ} \mathrm{x} 0.25^{\circ}$ spatial resolution for the 2000s.

indicate only a moderate increase. These annual changes mask changes occurring at the seasonal time scale. Under the extreme emission scenario, $M t$ decreases during the warmest summer months (June-September) by the 2080s and increases during the mild transition months (April and October-November) over northern Europe (Fig. 5a). The simulated decrease in $M t$ for the summer months is mainly related to simulated drier and warmer conditions, while the increase in $M t$ during April and October-November is due to more favourable temperature conditions (above the $+10^{\circ} \mathrm{C}$ isotherm - not shown). The simulated increase during the mild transition months is larger than the simulated decrease for the summer months, leading to an overall annual increase in $M t$ and this is consistent with results shown in Fig. 1. Under the lowest scenario, $M t$ is simulated to slightly increase in May and October over northern Europe (Fig. 5a). Southern Europe shows a different profile (Fig. 5b). According to this model, the current climatic conditions are far too dry for the development of the parasite during the warmest summer months in most of southern Europe and maximum $M t$ values are simulated during April-May and the September-November period. Considering both RCP-2.6 and RCP-8.5 emission scenarios for the 2080s, climatic conditions become even less suitable over the summer months (due to increasingly dry conditions; not shown), while risk is simulated to increase during the coldest seasons (autumn and winter) for southern Europe (since simulated future temperatures remain above the $+10{ }^{\circ} \mathrm{C}$ threshold). These $M t$ values are relatively small in magnitude compared to those shown for the north-western and central regions of Europe (Fig. 5b versus Fig. 5a).

\section{Discussion}

The European climate over the past four decades appears to be highly suitable for the development of 


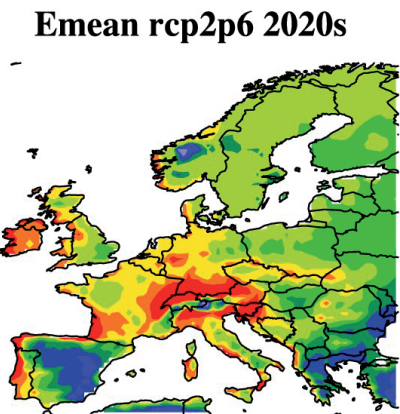

Emean rcp2p6 2050s

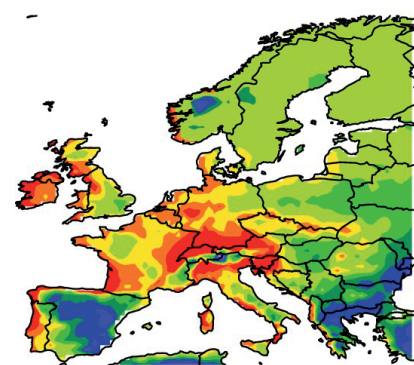

Emean rcp2p6 2080s

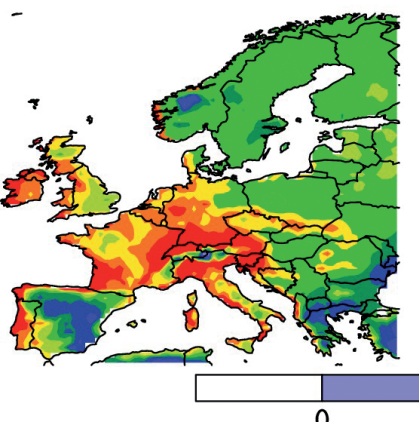

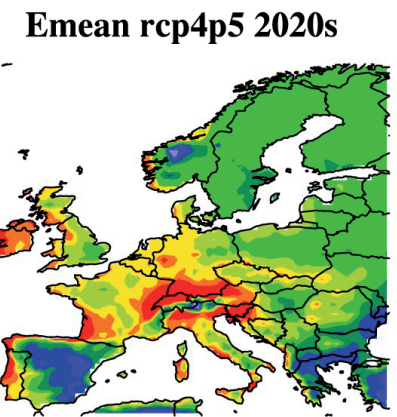

Emean rcp4p5 2050s

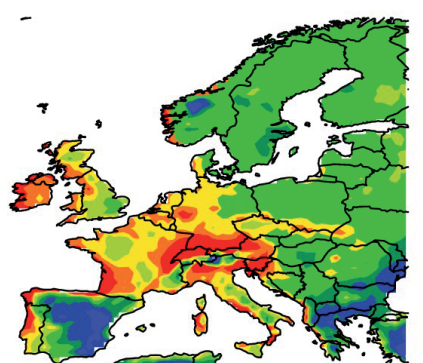

Emean rcp4p5 2080s

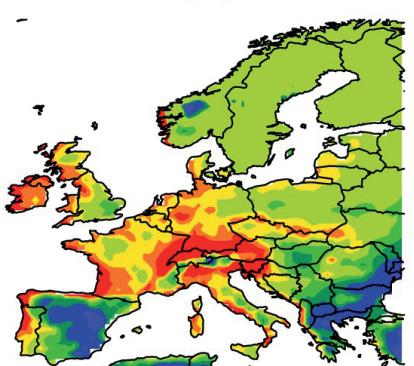

Emean rcp6p0 2020s

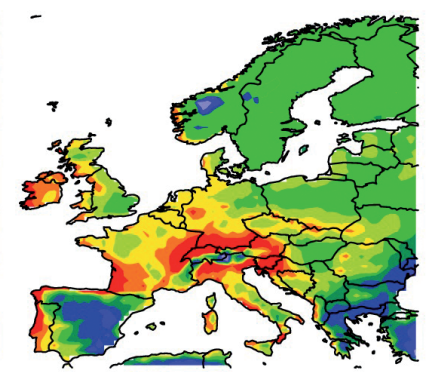

Emean rcp6p0 2050s

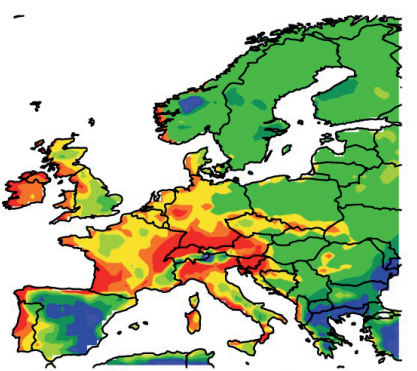

Emean rcp6p0 2080s

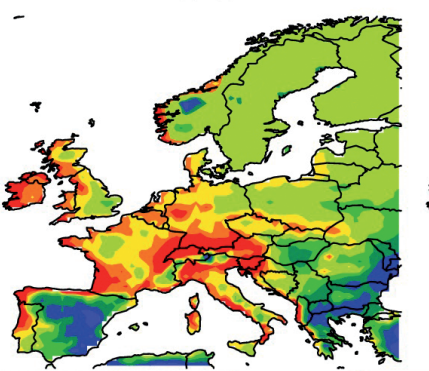

Emean rcp8p5 2020s

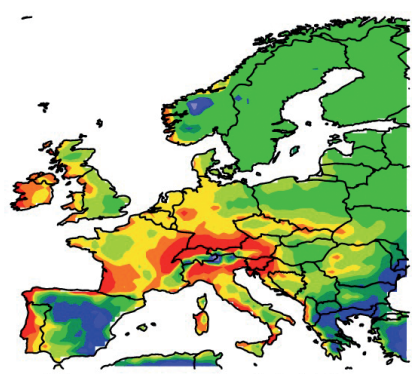

Emean rcp8p5 2050s

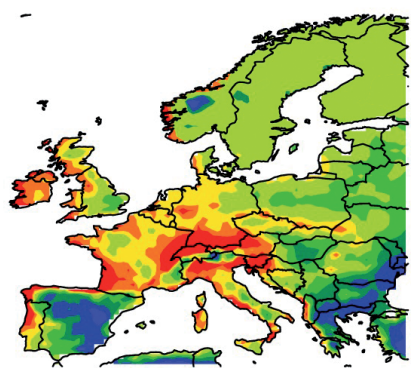

Emean rcp8p5 2080s

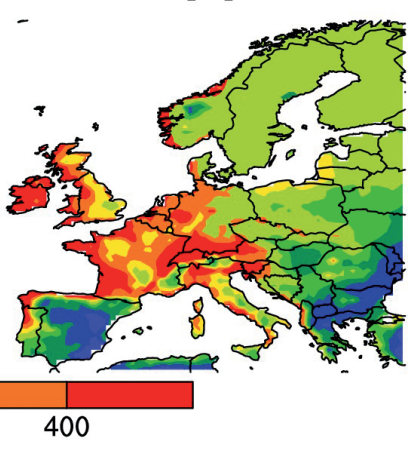

Fig. 4. Future simulated $M t$ risk based on the ensemble mean of five climate models. Results for annual F. hepatica infections for different decades (row) and different emission scenarios (column) with the lowest to the highest RCP emission scenario from left to right. The $M t$ values should be compared to the four critical thresholds given in the model description.

the parasite and its intermediate snail hosts, and the most favourable areas coincide with regions with large densities of cattle and small ruminants (Figs. 1 and 2). This is apparent for northern Spain, northern Portugal and western France, where the high $M t$ values are consistent with historical hotpots of human fasciolosis (Mas-Coma et al., 2005). Presumably, the prevailing climatic conditions do not only favour the parasite, but also herbage growth. Northern European countries experience more animal infections, obviously due to larger animal populations (Mas-Coma et al., 2005), while small numbers of human infections have also been reported from Austria, Belgium, Germany, Ireland, Italy, The Netherlands, Poland, Sweden, Switzerland and the UK (Esteban et al., 1998).

The model predicted that the climatic conditions would become more favourable for the spread of fasciolosis over central and north-western Europe during the 2000s with an expanding northern distribu- tion, which is consistent with the rising observed numbers of animal and human cases (Mas-Coma et al., 1999; van Dijk et al., 2010). This occurred in conjunction with other important factors such as reports of resistance to triclabendazole (Brennan et al., 2007). We further demonstrate that climate change is likely to impact the seasonality of fasciolosis in the future. The risk is projected to decrease during the warmest summer months due to drier conditions, while simulated to increase during the mild early spring and autumn months (April-May and October-November) due to more favourable temperature conditions over the wet regions of north-western and central Europe. This result is based on the most extreme emission scenario for the 2080s. When the lowest emission scenario is considered, future expected changes are relatively modest with only a small increase in risk shown for April and October in northern Europe.

There are important limitations to the application of 
a) Northern Europe
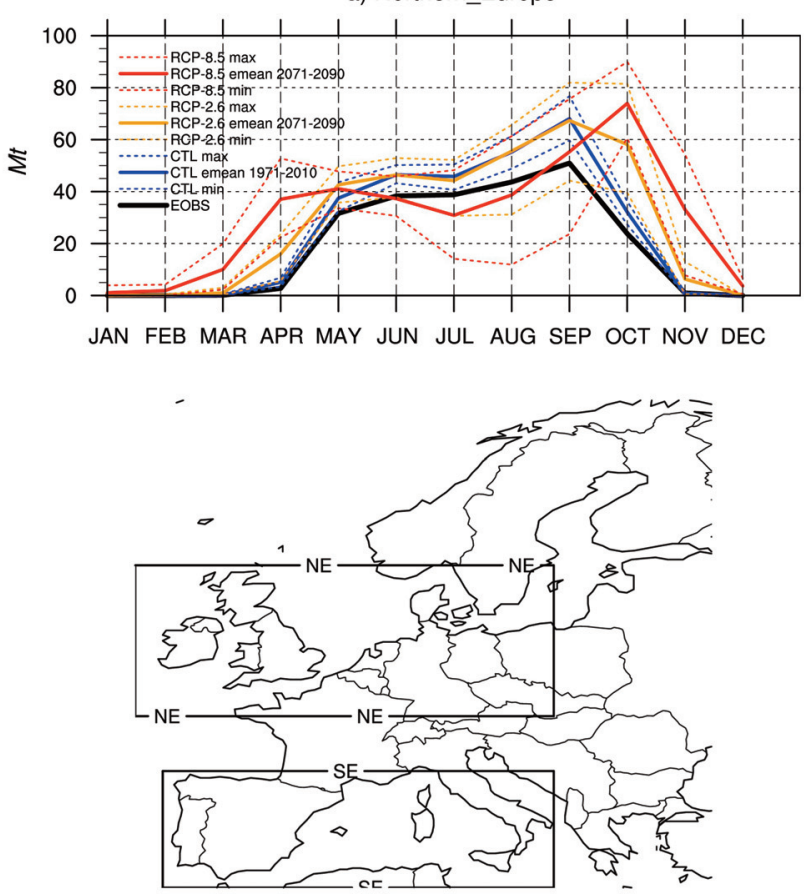

b) Southern Europe

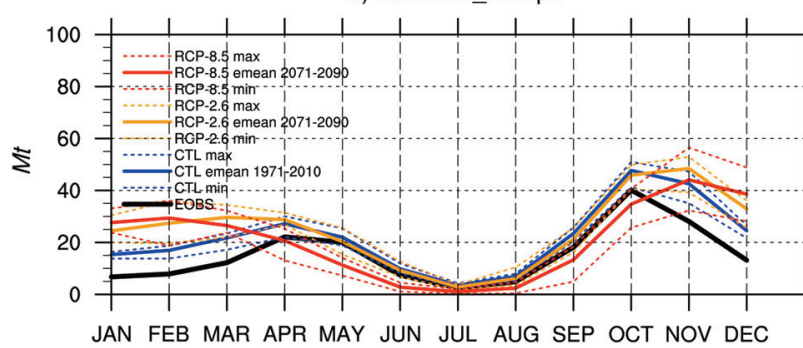

Legend:

Northern Europe: within $48^{\circ} \mathrm{N}-59^{\circ} \mathrm{N}, 12^{\circ} \mathrm{W}-18.5^{\circ} \mathrm{E}$; southern Europe: within $35.5^{\circ} \mathrm{N}-44^{\circ} \mathrm{N}, 10^{\circ} \mathrm{W}-18.5^{\circ} \mathrm{E}$. The black, solid line represents the "1971-2010 average" of the Mt model driven by EOBS climate observations.

Blue lines $=$ the $M t$ model driven by 5 climate models over the same time period.

Orange line $=$ the $M t$ model driven by 5 climate models for the RCP-2.6 emission scenario for the period 2071-2090.

Red lines $=$ the $M t$ model driven by 5 climate models for the RCP8.5 emission scenario for the period 2071-2090.

(Solid lines show the ensemble mean with dotted lines showing the minimum and maximum values within the model ensemble to assess the relative uncertainties).

Fig. 5. Change in $M t$ seasonality for northern and southern Europe under various scenarios.

the $M t$ model to future climate scenarios at the wider European scale, because we used a model originally developed for Wales, which was also successfully employed as an early warning forecasting system for the UK (NADIS, 2014). Thus, the risk calculated at the pan-European level has been assumed to be subject to the same climatic drivers as in the UK. The $M t$ model is mainly based on rainfall data and it only includes temperature as a threshold value for development of the parasite and as an estimate of potential evapotranspiration. Other methods for the calculation of evapotranspiration should be tested such as the PenmanMonteith equation which is the "gold standard" method used by the Food and Agriculture Organization (FAO) (Allen et al., 1998). Furthermore, the model does not consider man-made irrigation, so the model may underestimate the risk for the drier southern European countries. Indeed, F. hepatica is also known to be a threat to animal health in warmer and more arid regions, such as Greece (Kantzoura et al., 2011) and Egypt (Haseeb et al., 2002). More complex process-based modelling approaches, driven by remote sensing data, should also be investigated (Charlier et al., 2014). In addition, the model does not consider other critical factors for the presence of the parasite, such as soil types and land use (McCann et al., 2010; Bennema et al., 2011; Charlier et al., 2011) or the potential of wild animal hosts, such as deer, rats, foxes, hares and rabbits that can act as reservoir in the absence of domestic ruminants (Rondelaud et al., 2001). Finally, the $M t$ model does not include the additional effects of climate change on farm management, possible anthelmintic resistance and land use. However, the availability of soil moisture will continue to be a key determinant of infection levels in animals and our scenarios appear to provide a robust starting point for estimations of future fasciolosis risk.

\section{Acknowledgments}

The authors acknowledge funding support from the GLOWORM EU-FP7 project (contract number FP7-KBBE-2011-5288975). We also acknowledge the ISI-MIP Fast Track project, funded by the German Federal Ministry of Education and Research (BMBF) with project funding reference number 01LS1201A, for providing the climate model experiments.

\section{References}

Allen RG, Pereira LS, Raes D, Smith M, 1998. Crop evapotranspiration: guidelines for computing crop requirements. FAO Irrigation and Drainage. Paper no. 56. FAO, Rome, Italy.

Behm CA, Sangster NC, 1999. Pathology, pathophysiology and clinical aspects. In: Fasciolosis. Dalton JP (ed). Wallingford, Oxon, UK: CABI Pub, 185-224 pp.

Bennema SC, Ducheyne E, Vercruysse J, Claerebout E, Hendrickx G, Charlier J, 2011. Relative importance of management, meteorological and environmental factors in the spa- 
tial distribution of Fasciola hepatica in dairy cattle in a temperate climate zone. Int J Parasitol 41, 225-233.

Brennan GP, Fairweather I, Trudgett A, Hoey E, McCoy, McConville M, Meaney M, Robinson M, McFerran N, Ryan L et al., 2007. Understanding triclabendazole resistance. Exp Mol Pathol 82, 104-109.

Charlier J, Bennema SC, Caron Y, Counotte M, Ducheyne E, Hendrickx G, Vercruysse J, 2011. Towards assessing fine-scale indicators for the spatial transmission risk of Fasciola hepatica in cattle. Geospat Health 5, 239-245.

Charlier J, Vercruysse J, Morgan E, van Dijk J, Williams DJL, 2014. Recent advances in the diagnosis, impact on production and prediction of Fasciola hepatica in cattle. Parasitology 141, 326-335.

Daniel R, van Dijk J, Jenkins T, Akca A, Mearns R, Williams DJL, 2012. A composite faecal egg count reduction test to detect resistance to triclabendazole in Fasciola hepatica. Vet Rec 171, 1-5.

Esteban JG, Bargues MD, Mas-Coma S, 1998. Geographic distribution, diagnostics and treatment of human fascioliasis: a review. Res Rev Parasitol 58, 13-42.

Fiss L, de Lourdes Adrien M, Marcolongo-Pereira C, AssisBrasil ND, Sallis ESV, Riet-Correa F, Ruas JL, Schild AL, 2013. Subacute and acute fasciolosis in sheep in southern Brazil. Parasitol Res 112, 883-887.

Fox NJ, White PCL, McClean CJ, Marion G, Evans A, Hutchings MR, 2011. Predicting impacts of climate change on Fasciola hepatica risk. PLoS One 6, e16126.

Hargreaves GH, Samani ZA, 1985. Reference crop evapotranspiration from temperature. Appl Eng Agric 1, 96-99.

Haseeb AN, El Shazly AM, Arafa MAS, Morsy ATA, 2002. A review on fascioliasis in Egypt. J Egypt Soc Parasitol 32, 317 354.

Haylock MR, Hofstra N, Klein Tank AMG, Klok EJ, Jones PD, New M, 2008. A European daily high-resolution gridded dataset of surface temperature and precipitation. J Geophys Res Atmos 113, D20119.

Hempel S, Frieler K, Warszawski L, Schewe J, Pontiek F, 2013. A trend-preserving bias correction - the ISI-MIP approach. Earth Syst Dyn 4, 219-236.

Kantsoura V, Kouam MK, Feidas H, Teofanova D, Theorodopoulos G, 2011. Geographic distribution modelling for ruminant liver flukes (Fasciola hepatica) in south-eastern Europe. Int J Parasitol 41, 747-753.

Kaplan RM, 2001. Fasciola hepatica: a review of the economic impact in cattle and considerations for control. Vet Ther 2, 40-
50.

Mas-Coma S, Bargues MD, Esteban JG, 1999. Human fasciolosis. In: Fasciolosis.Dalton, JP (ed). Wallingford, Oxon, UK: CABI Pub, 411-434 pp.

Mas-Coma S, Bargues MD, Valero MA, 2005. Fascioliasis and other plant-borne trematode zoonoses. Int J Parasitol 35, 1255-1278.

McCann CM, Baylis M, Williams DJL, 2010. The development of linear regression models using environmental variables to explain the spatial distribution of Fasciola hepatica infection in dairy herds in England and Wales. Int J Parasitol 40, 10211028.

Moss RH, Edmonds JA, Hibbard KA, Manning MR, Rose SK, van Vuuren P, Carter TR, Emori S, Kainuma M, Kram T et al., 2010. The next generations of scenarios for climate change research and assessment. Nature 463, 747-756.

NADIS parasite forecasts, 2014. Available at: http://www.nadis.org.uk/parasite-forecast.aspx (accessed on February 2015).

Ollerenshaw CB, Rowlands WT, 1959. A method of forecasting the incidence of fascioliasis in Anglesey. Vet Rec 71, 591-598. Robinson TP, Wint GRW, Conchedda G, Van Boeckel TP, Ercoli V, Palamara E, Cinardi G, D’Aietti L, Hay SI, Gilbert M, 2014. Mapping the global distribution of livestock. PLoS One 9, e96084.

Rondelaud D, Vignoles P, Abrous M, Dreyfuss G, 2001. The definitive and intermediate hosts of Fasciola hepatica in the natural watercress beds in central France. Parasitol Res 87, 475-478.

Sargison ND, Jackson F, Bartley DJ, Wilson DJ, Stenhouse LJ, Penny CD, 2007. Observations on the emergence of multiple anthelmintic resistance in sheep flocks in the south-east of Scotland. Vet Parasitol 145, 65-76.

Taylor KE, Stouffer RJ, Meehl GA, 2012. An overview of CMIP5 and the experiment design. Bull Am Met Soc 93, 485498.

van Dijk J, Sargison ND, Kenyon F, Skuce P, 2010. Climate change and infectious disease: helminthological challenge to farmed ruminants in temperate regions. Animal 4, 377-392.

Warszawski L, Frieler K, Huber V, Pontiek F, Serdeczny O, Schewe J, 2014. The Inter-Sectoral Impact Model Intercomparison Project (ISI-MIP): Project framework. Proc Nat Ac Sc U S A 111, 3228-3232.

WATFLOOD, 2002. User manual. Available at: http://www.civil.uwaterloo.ca/watflood/Manual/02_03_2.htm (accessed on February 2015). 